\section{El Kruce de los Andes: memoria de San Martín y discurso político en Revolución (Ipiña, 2010)}

Tzvi Tal *

\begin{abstract}
Resumen: La figura del Libertador General José de San Martín fue incorporada al Panteón de los Héroes Nacionales de la Republica Argentina hacia 1870, mucho después de la gesta emancipadora. Su memoria fue consagrada, institucionalizada y toda imagen alternativa penalizada, pese a lo cual la cambiante imagen cinematográfica del Prócer testimonia los giros en el discurso que los conflictos sociales y políticos generaban. Este artículo sostiene que reconstruyendo la imagen del Libertador, la película Revolución: El cruce de los Andes (Ipiña, 2010) difunde el discurso del fallecido presidente Néstor Kirchner y de la presidente en ejercicio Cristina Fernández de Kirchner, también apodado "discurso K”. El film manifiesta la reconstrucción de la identidad argentina convocada por el discurso K y el bloque histórico constituido en torno a su proyecto.
\end{abstract}

Palabras clave: cine - discurso - identidad - Kirchner - San Martín.

[Resúmenes en inglés y portugués en la página 253]

${ }^{(*)}$ Profesor en la Escuela para las Artes del Sonido y la Imagen en el Colegio Académico Sapir y otras universidades en Israel. Autor de diversos artículos, sus investigaciones enfocan las relaciones entre el Cine y los procesos de la Identidad Nacional, la Etnicidad, la Historia y los Discursos en el ámbito Ibero-Latinoamericano.

\title{
Introducción
}

La película Revolución: El cruce de los Andes (Ipiña, Argentina, 2010) producida y distribuida con apoyo del Gobierno Nacional Argentino durante la presidencia de Cristina Fernández de Kirchner, relata el cruce de la cordillera de los Andes en 1817 bajo el comando del General José de San Martín con el objeto de expulsar a las fuerzas realistas de la vecina Chile. Revisando aspectos del proceso de producción, considerando la recepción del film en la esfera pública y política argentina, y analizando el texto cinematográfico, este artículo sostiene que la reconstrucción de la imagen del personaje histórico difunde el discurso kirchnerista, cuyo portavoz mas notorio, luego del fallecimiento de Néstor Kirchner, es la Presidenta en ejercicio Cristina Fernández de Kirchner. El discurso K, apodo que designa la expresión del proceso conducido por el matrimonio Kirchner y el bloque histórico aglomerado bajo su liderazgo, se apropia de la figura de San Martín, consagrado como El 
Libertador y también como Padre de la Patria, para establecer paralelos entre el finado ex presidente Kirchner y el Prócer. El discurso concibe la sociedad argentina como fraccionada en campos opuestos dicotómicos y tiende a menospreciar la legitimidad de sus opositores mientras invoca la vocación de unión atribuida al legado histórico de San Martín.

\section{Globalización y neocolonialismo cinematográfico}

La producción cinematográfica en los países del continente latinoamericano se ha visto perjudicada por las consecuencias de la globalización y la hegemonización de los modos de representación habituales en el cine distribuido por las empresas trasnacionales que monopolizan los contenidos audiovisuales, a tal punto que gran parte de las producciones locales se concretan sólo cuando logran movilizar el apoyo de fondos económicos transnacionales como Ibermedia, fundado por los gobiernos de España y países del Cono Sur en 1995 con el objeto de estimular la coproducción fílmica con capitales españoles privados. Puesto en funcionamiento en 1998, Ibermedia ha contribuido a la revitalización de la producción latinoamericana, apoyando en su primer decenio más de mil proyectos, entre ellos la coproducción de 348 películas. Su acción parece consolidar el establecimiento del neoliberalismo en el campo de la producción audiovisual, pero también a despertado críticas a cierta falta de trasparencia en la elección de proyectos. Una de las consecuencias visibles de la política de coproducción es el condicionamiento de las narrativas a las exigencias de las productoras españolas y la frecuente aparición de personajes y actores españoles en películas latinoamericanas. Por ejemplo, la cineasta uruguaya Beatriz Flores buscó seis años la inversión necesaria para realizar En la puta vida (2001), finalmente obtenida mediante Ibermedia, con capitales de Uruguay, España, Bélgica y Cuba. Los intereses extranjeros exigieron trasladar a Barcelona la trama ubicada originalmente en Italia, y bajo exigencias del actor español que desempeña el rol de policía redentor de la prostituta uruguaya, se introdujeron cambios en la escena final, con cuya planificación no estaba conforme (Alvarez Valencia et al, 2009; Falicov, 2007; Villazana, 2009; Tal, 2011).

El establecimiento de Ibermedia cuando la economía española parecía ser una de las más pujantes en el marco de la Unión Europea, expresó la aspiración de consolidar vínculos con el mundo hispano-parlante, estimado en 400 millones de personas, como los mantenidos por Francia y Gran Bretaña con sus antiguas colonias. Empresas españolas conquistaron prominentes posiciones en diversos campos de las economías de América Latina, como el control sobre las empresas de aviación civil LAN Chile y Aerolíneas Argentinas y de la empresa Yacimientos Petrolíferos Fiscales de explotación de hidrocarburos en Argentina. Este proceso reprodujo algunos aspectos de la dependencia neo-colonial, como el giro de la mayor parte de las ganancias a la empresa madre en Europa (Página 12 2/5/2012). Al incentivar la actividad cinematográfica, que es una de las plataformas de construcción y difusión de los imaginarios con los que las sociedades elaboran sus identidades, se benefician la cultura y también la elite cultural e intelectual de cineastas y productores, pero dichos logros están condicionados por la voluntad estatal española de consolidar su liderazgo a nivel internacional (Mar-Molinero, 2006). 
La producción del film acerca de la gesta de San Martín era parte de un proyecto cinematográfico impulsado desde mediados de la década del 2000 por las productoras españolas Wanda Films y Lusa Films, con el apoyo de Televisión Española, Ibermedia y una serie de instancias gubernamentales españolas: Secretaría General Iberoamericana, Secretaría de Estado para Iberoamérica, Dirección de Relaciones Culturales y Científicas de la Agencia Española de Cooperación Internacional para el Desarrollo, Comisión del Bicentenario, Instituto Cervantes, Sociedad Estatal para la Acción Cultural Exterior y Sociedad Estatal de Conmemoraciones Culturales. El Proyecto Libertadores constaba de 8 películas, a través de las cuales - de acuerdo a los organizadores- se daría a conocer el pensamiento y obra "de las figuras más relevantes de la lucha por la emancipación de América Latina", haciendo especial hincapié no sólo en los hechos históricos, sino sobre todo en las facetas humanas y sus ideologías de carácter libertador. Los productores sostenían que "los Libertadores seleccionados estaban ligados a España no sólo por las circunstancias políticas o por el idioma, sino también porque las ideas que alimentaron su pensamiento viajaron de un lado a otro del Atlántico". Cada héroe sería propuesto como quien encaraba la acción revolucionaria aspirando a la liberación de la humanidad, representada en primer lugar por la de su Nación: José Martí en Cuba, José de San Martín en Argentina, José Gervasio Artigas en Uruguay, el cura Hidalgo en México, Joaquín José da Silva 'Tiradentes' en Brasil, Bernardo O’Higgins en Chile, Simón Bolivar Venezuela y Tupac Amaru en Perú. Las ocho películas se rodarían en los países de origen de cada Libertador, dirigidas por destacados directores de cada país y con la participación de actores profesionales, para ser estrenadas por televisión en España, y en cine y televisión en América Latina y el resto del mundo (www.loslibertadores.net; www.wandafilms.com; www.empresite.com). El proyecto Libertadores expresa la intención de construir un espacio cultural ibero-americano liderado por la antigua potencia colonial, para lo cual la imagen neocolonial de la Madre Patria europea es sustituida con una más apropiada que resalta la interacción ideológica entre las culturas a ambos márgenes del Atlántico.

Entre los socios argentinos, el proyecto fue mutando. En principio se produjeron programas especiales sobre las batallas, capítulos de docudrama que luego devinieron en ficción con El Combate de San Lorenzo, producción del Canal Encuentro dirigida por el mismo Ipiña, transmitida en 2008 y retransmitida el 17 de agosto de 2010, al cumplirse 160 años de la muerte del Prócer (http://sur.infonews.com; www.encuentro.gov.ar). Revolución fue finalmente producida y financiada por los entes estatales argentinos Televisión Pública y Canal Encuentro, con el apoyo del Instituto Nacional de Cine y Artes Audiovisuales, el Gobierno de la provincia de San Juan, la Universidad Nacional de San Martín y Televisión Española. La participación de las productoras españolas Wanda y Luso es acreditada muy discretamente al final del film, mientras que Ibermedia no participó. De este modo, la película es un producto audiovisual totalmente argentino, liberado de las condiciones dependientes frecuentes en los proyectos apoyados por el fondo transnacional (www.programaibermedia.com). ${ }^{1}$

De la intencionalidad del proyecto se desprende también la estética adoptada para el film: drama épico histórico con algunas escenas de acción, en el modo de representación realista habitual en los productos cinematográficos destinados a la comercialización en las redes 
globales. Dicho modo ha hegemonizado el gusto de las audiencias, manifestándose en un lenguaje cinematográfico que permite la identificación sin despertar conciencia crítica (Comolli \& Narboni, 1969, 1985). La exhibición de Revolución logró amplia repercusión en los medios y entre los espectadores, recaudando en sus primeros cuatro días de exhibición comercial algo más del 10\% del total del costo. Fue también distribuida a instituciones educativas en todos los niveles, así como a agrupaciones públicas y políticas. El Ministerio de Educación transformó el film en una empresa pedagógica nacional, publicando un libro con propuestas para su uso educativo en las escuelas, que presenta película como una metáfora de la revolución donde cada personaje representa un estrato social, y también como un punto de vista para discutir la historia, pues, en palabras de la publicación, "pensar el pasado es comprender el presente y preveer el futuro" (Di Meglio, 2010).

\section{Del pasado a las pantallas, de la gloria a la política}

La presidenta presenció el film en noviembre de 2010, en un evento en conmemoración del Bicentenario de la Independencia, previo al estreno, donde también se recordó al finado Néstor Kirchner. En esa oportunidad afirmó que los próceres que lucharon por la liberación de Sudamérica "... fueron hombres de carne y hueso que enfrentaron adversidades $y$ virtudes y miserias para poder afrontar un proceso que los hizo ingresar definitivamente en la historia" (www.perfil.com 14/8/2009). Otros funcionarios del campo de la cultura y el cine establecieron en sus alusiones la conexión que perciben entre el Padre de la Patria y la memoria del ex presidente fallecido. La presidenta del Instituto Nacional de Cine y Artes Audiovisuales mencionó dicho nexo como imprescindible; el secretario de Cultura de la Nación recordó que Kirchner había impulsado la política cinematográfica que incentivó la producción, y el titular del Sistema Nacional de Medios Públicos, agregó que la película

... tiene que ver con una línea que nos marcó Néstor Kirchner y nos marca la presidenta Cristina Fernández para que las pantallas argentinas tengan una función social y sirvan para el pueblo. Nuestro compromiso es seguir adelante para que estas imágenes se transformen en ideas (www.26noticias.com.ar).

Expresando el giro antes mencionado en la concepción del espacio iberoamericano, el director del film dijo que "no fue una guerra contra España o los españoles en particular, sino más bien en contra de un sistema de gobierno opresor". Por su parte, el actor protagonista consideró que

San Martín fue un hombre fuera de época, que encarnó una verdadera revolución continental para luchar contra un sistema de castas injusto, un sistema de masacres y barbarie. Su legado repercute hoy más que nunca en Latinoamérica y en todo el mundo (Rockandball. Periodismo sin filtro). 
En sus palabras, tanto el director como el actor expresan claramente la apropiación del legado del Héroe por el discurso K, que se propone como alternativa a las atrocidades sociales causadas por la aplicación del neoliberalismo durante la década de los noventa (www.perfil.com; www.encuentro.gov.ar).

El director Ipiña declaró en otra oportunidad que la filmación transcurrió en una libertad absoluta, y que "desde el gobierno nacional sólo se habían recibidos elogios" (www. rockandball.com.ar), pero no deja de llamar la atención la coincidencia entre los intereses gubernamentales y la postura de agentes sociales activos en el campo cinematográfico, que deben ser entendidos como lo que Antonio Gramsci llamaba 'intelectuales orgánicos', en este caso, identificados con el bloque histórico constituido en torno al discurso K. Gramsci también sostenía que la ideología hegemónica se disimula bajo la apariencia de la lógica cotidiana. En este caso, el comentario del film en el diario Página 12 contribuye al ocultamiento de la ideología sosteniendo que “...la película buscará centrarse en un relato de acción antes que político. Su segundo acierto consiste en evitar un narrador histórico, omnisciente y distante...”, para concluir “...la Historia no es monopolio de los jetones, sino que se levanta sobre las espaldas de hombres sin rostro, cuyas voluntades se ofrecieron a la causa de la patria, tal vez sin saber muy bien qué es exactamente una patria" (Página 12 7/4/2011). Analizando el modo de reproducción de la ideología en la conciencia del sujeto, Louis Altousser señalaba como mecanismo esencial la convocatoria o interpelación del individuo por las instituciones sociales, en cuyas funciones esta impregnada la ideología dominante. El ocultamiento de si misma es una estrategia que permite construir el sujeto conforme sin despertar resistencia. En este caso, esta disimulada en la apologética del ciudadano anónimo a quién hay que enseñar que es una patria, de acuerdo a la versión del discurso K embebido en el texto cinematográfico producido por las instituciones que domina (Portelli, 1974; Althusser, 1971; Cinelli, 2011).

La instrumentación de la memoria del Libertador en las películas históricas producidas durante los últimos cincuenta años testimonia los giros discursivos y combates simbólicos que sacudieron a la cultura argentina. Las películas El santo de la espada (Torre Nilsson, 1968) y La hora de los hornos (Grupo Cine Liberación, 1969) coinciden en acentuar aspectos militares de la personalidad del Héroe, mientras manifiestan el conflicto entre el discurso de la dictadura del General Onganía y el de la lucha armada peronista revolucionaria de Montoneros. El primero adaptó la figura histórica al ethos que legitima la intervención del ejército en la vida política nacional instituyendo gobiernos de facto y disciplinando a la sociedad mediante la hegemonización del discurso moralizante católico y anticomunista. El segundo se apropió en forma selectiva de citas y dichos del Libertador para justificar la lucha armada revolucionaria, que sería la continuación de la Primera Guerra de Liberación Nacional conducida por San Martín un siglo y medio antes. En ambos casos se acentúan los aspectos militares del Prócer: el discurso de la dictadura reafirmando la hegemonía del bloque histórico cuyo eje era la oligarquía agrícola-ganadera, mientras que el discurso montonero construía una contra-historia mediante la interpretación en modo contestatario de los textos y documentos consagrados (Tal, 2004).

La invocación de la memoria de San Martín fue instrumentada tanto por la dictadura instaurada en 1976 para justificar el exterminio del enemigo interno, como por los voceros que lo recordaban para consolidar la democracia recuperada en 1983 (Philp, 2009), 
pero sólo dos décadas mas tarde volvió el Libertador a las pantallas en El general y la fiebre (1992). Esta película expresó la desilusión del discurso nacionalista-marxista-peronista enraizado en los textos del historiador Abelardo Ramos ante el giro neoliberal y globalizador impulsado por el gobierno del presidente Carlos Menem, mediante la imagen de San Martín acosado por alucinaciones febriles y miedos. Dirigida por Jorge Coscia, posteriormente nombrado Secretario de Cultura por Fernández de Krichner, El general y la fiebre ubica la visión del Libertador en un breve período poco conocido de enfermedad, narrado desde el punto de vista de la sirvienta indígena, una excluida tanto por su género como por su identidad étnica. En oposición a la imagen mediática de Menem y su modo autoritario de gobierno por decreto, la película representa a San Martín convocado a conducir el cruce de los Andes por indígenas que lo interpelan en la lengua quechua de Tupac Amaru. Paradójicamente, San Martín no es nombrado en la película, no solo para evitar posibles interferencias del Instituto Nacional Sanmartiniano, dueño del monopolio sobre la memoria del Libertador, sino también como recurso estético que facilita la analogía entre dos generales, San Martín y Perón. La imagen de San Martín en El general y la fiebre se alinea con la inclinación a desmonumentalizar la imagen de los Próceres que surgió en la novelística y la prosa historiográfica latinoamericana bajo la globalización, expresando así la negociación de un discurso minoritario y marginal bajo la hegemonía neoliberal (Tal, 2010b). La referencia de la presidenta a 'héroes de carne y hueso' no es ajena a esta inclinación, y sugiere implícitamente cierta flexibilidad para con otras debilidades, como las que se revelan en las intersecciones entre la política, el poder y los grandes negocios en la era actual. Paradójicamente, esa indulgencia se aparea con algunas similitudes entre el culto de la persona de Kirchner y el fundamentalismo religioso, donde predomina el pensamiento mágico que impermeabiliza al colectivo con respecto al principio de realidad haciendo converger la negación, la victimización y la deshumanización. La percepción de los Otros como amenaza a los valores propios genera hostilidad, de modo que lo Político es conceptualizado como una dimensión antagónica y la Política como las prácticas destinadas a crear un nuevo orden, un mundo comprensible. Mientras que en la democracia debería verse a los Otros como adversarios y no como enemigos, todo movimiento con vocación de masas convoca al pueblo contra algún enemigo (Korstanje, 2011).

\section{DisKurso y Memoria}

La comprensión del sentido de la imagen del Libertador en Revolución requiere conocer las características del Discurso K y el modo de construcción de la memoria histórica que practica. Tanto Néstor Kirchner durante su gobierno, como la presidenta Fernández de Kirchner, manifiestan una tendencia a la exclusión de los adversarios políticos y a la idealización de la persona del Presidente Kirchner y de su actuación al frente del Estado. Ambos construyen lo político apelando a una mezcla de religiosidad y argumentación con un fuerte sesgo emocional y estético enraizado en la década de los setenta (Korstanje, 2011). El discurso de Néstor Kirchner respecto a los desocupados y el activismo piquetero, problemas candentes luego de la crisis económica de 2001, identificaba al pueblo como víctima y como fuente de la soberanía, caracterizando al gobierno como genuino 
representante de los intereses populares. Identificaba al neoliberalismo y las reformas económicas en la década del noventa como el enemigo causante de los daños sufridos por el pueblo y definía a su gobierno como redentor, para lo cual contaba con el Estado como herramienta (Muñoz y Retamozo, 2008). La situación anterior a 2001 era descrita por Néstor Kirchner como un pasado nefasto, ante el cual se presentaba a sí mismo como antítesis de la hegemonía anterior; como la figura que "suturaba a la comunidad herida"; cuyo discurso articuló múltiples sentidos disponibles, presentándose como respuesta a la dislocación social y política (Magrini y Quiroga, 2011).

El discurso de Cristina Fernández de Kirchner se concentraba, al principio de su gobierno, en reafirmar su propia persona y mantener el índice de popularidad, sin lograr modificar la agenda del discurso dominante. Como en otros gobiernos neo-populistas latinoamericanos, la ampliación de los derechos sociales y políticos gestionados por los gobiernos $\mathrm{K}$ no parece estar en relación directa con el alcance de los cambios que se introducen en el sistema institucional. Las innovaciones que introducen en el acceso a bienes y servicios, el empoderamiento de sectores populares y la conquista de mayor igualdad, pueden ser recursos circunstanciales para legitimar la puesta del aparato estatal en manos de partidarios de confianza y las limitaciones impuestas al pluralismo en la competencia por el control de dicho aparato. En ese contexto, la presidenta continúa la retórica dicotómica, como durante la crisis del agro en 2008, cuando se proponía en sus discursos como única alternativa frente al golpe reaccionario que estaría gestándose (Raiter, 2009).

Algunas medidas de la segunda presidencia de Cristina Fernández de Kirchner, como la renacionalización parcial de la explotación de los hidrocarburos en 2012, pueden atribuirse al intento de asentar su innegable popularidad en cambios económicos estructurales concretos, pero también revisten un carácter ideológico explicitado por el jefe de la Comisión de Relaciones Exteriores del Senado de la Nación al ponderar el éxito K en la recuperación por el pueblo argentino de la concepción que el Estado debe jugar un rol preponderante en la conducción del modelo de desarrollo económico-social y la gestión de los recursos imprescindibles a tal efecto (Página 12 25/4/2012).

La estrategia retórica que describe la sociedad argentina como fragmentada en forma dicotómica entre Nosotros y Enemigos fue practicada por el peronismo durante los primeros gobiernos de Juan Domingo Perón (1946-1955), y por los partidarios de Perón en los años setenta, en consignas como Braden o Perón, Pueblo y Antipueblo, Liberación o Dependencia, etc. La memoria de la militancia peronista setentista constituye la memoria del discurso K, estableciéndose continuidades y recurrencias entre ambas series de discursos. La evocación de la militancia peronista de los setenta construye un ethos discursivo militante, informal, juvenil, transgresor y beligerante, que polariza la vida política entre un bando autoritario y antidemocrático, el de sus adversarios potenciales o efectivos, y otro popular, hegemonizado por él mismo, cuyas raíces se hallan en aquella generación combativa (Montero, 2009).

La construcción del pasado por el discurso y el Culto K apela a la memoria para alimentar el miedo político como arma de disuasión y persuasión. La década de los 90 representó para el imaginario argentino un trauma que dio lugar al nacimiento del culto y a su teoría conspirativa: los poderes internacionales y los organismos financieros, con la complicidad de la elite empresaria local, hundieron a la Argentina en la pobreza. El modelo neoliberal 
y el reclamo por los derechos humanos de los Desaparecidos y sus familias se transformaron en una razón política de Estado para la concreción de metas específicas y correctivas, como reestablecer la grandeza de la Nación y fomentar un modelo de inclusión social de todas las clases relegadas. El culto K permite a personas corrientes sentirse protagonistas de una era, de un sentir y de un rumbo hacia la felicidad. Este sentimiento cumple una función catártica, como el arte o del deporte, ya que saca el sujeto de su anonimato y lo recoloca transformado en un ente necesitado de reconocimiento. Cristina Fernández y Néstor Kirchner se transformaron en los héroes míticos que podrían sacar el pueblo argentino del letargo en donde se encontraba. Este proceso de apoteosis culminó con la muerte del ex presidente Néstor Kirchner, al agregar inesperadamente un aspecto de sacrificio. Lo estético, por su parte, se desborda en los escenarios patrios y las fiestas populares como rituales de grandeza, en la teatralización de la vida política (Korstanje, 2011).

La crisis social que explotó en 2001 damnificó particularmente a las clases medias argentinas, que sufrían orfandad política luego de las frustraciones impartidas por la hiperinflación en los ochenta y el menemismo en los noventa. El discurso y el culto K gozan de una base de sustento político mucho más heterogénea que gobiernos anteriores, pero no logran generar la confianza de las clases medias, cuya inestabilidad y falta de perspectiva de futuro son una amenaza latente a la estabilidad que todo gobierno aspira a preservar. El discurso K relega la iconografía peronista en su apelación política, de modo que ya no postula la anterior dicotomía peronismo-antiperonismo, que alejaría a las clases medias. En su lugar, postula la conflictividad entre el polo de centro-derecha y el polo de centro-izquierda aglutinado en torno a Néstor Kirchner. Ante ese futuro percibido como amenaza, la imagen de San Martín humano y vencedor, es un factor que convoca y despierta confianza, pues aunque ya fue utilizado en el pasado por el peronismo, sigue siendo una figura consagrada por encima de los conflictos políticos. En este caso, su memoria cinematográfica difunde alegóricamente la superioridad moral manifestada por Néstor Kirchner para auto-presentarse positivamente y diferenciarse de los anteriores gobiernos y representa la tendencia del discurso K a postularse como fundador del Estado (De Riz en Hopenhayn et al, 2010; Rocca Rivarola en Cheresky, 2001; Bietti, 2009; Sarlo, 2004).

\section{Patria y peripecia}

La decisión del Libertador de cruzar los Andes tuvo como fondo la controversia entre los gobernantes del Río de la Plata en torno a si se utilizaba el ejército en las disputas internas o en perseguir y atacar a las fuerzas realistas. San Martín aprovechó la fragmentación política para ganar autonomía y realizar su plan estratégico (Lynch, 2009). Enfocando en la gesta del cruce de la Cordillera, la película construye una analogía entre el proyecto del Liberador y la gestión $\mathrm{K}$, que pretende unificar e incluir a los sectores excluidos y relegados, enfrentando factores de poder opositor imponentes como la Cordillera. La reproducción cinematográfica de sucesos históricos documentados investidos de sentido presente se encuadra en la categoría de alegoría pragmática, estrategia retórica conocida en el tratamiento fílmico de acontecimientos traumáticos del pasado argentino. El carácter alegórico no debe ser encarado revisando la intencionalidad de quienes producen el film, sino que 
son las discontinuidades e incoherencias textuales las que invitan al espectador a producir una lectura alegórica (Xavier en Stam and Miller, 1999). 2 En el caso de este film, las discontinuidades son los vaivenes esporádicos entre dos tiempos, 1817 y 1880; los titulares mencionando hitos históricos marcan discontinuidades en el desarrollo de la trama; y en la banda de sonido se escuchan dos relatores distintos: Corvalán viejo, y la locución del mismo San Martín con acento castizo, por ejemplo de la convocatoria al pueblo chileno en el minuto 61', o la carta informando el triunfo en Chacabuco en el minuto 82'.

El título Revolución - El cruce de los Andes, crea asociación entre la operación militar del pasado y el discurso K, a quien autores como Julio Godio le atribuyen realizar una "revolución desde arriba", pero con la vocación de transformarla en "revolución desde abajo"(Godio, 2006). La actuación de Rodrigo de la Serna como San Martín le aporta cierta aura revolucionaria originada en su anterior actuación como compañero de la travesía de Che Guevara en el film Diarios de motocicleta (Walter Salles, Argentina, Brasil, Chile, Alemania, Perú, Francia, Reino Unido, Estados Unidos, 2004). ${ }^{3}$

La estructura narrativa de relato dentro de otro relato, surge cuando el viejo general Corvalán narra en 1880 la gesta del cruce del los Andes en 1817, cuando era secretario de San Martín. Corvalán es un personaje de características contradictorias: por un lado, es el adolescente que aprende a valorar de cerca las cualidades militares del Libertador como agudo estratega, exigente oficial y hombre de acción, pero también sus aspectos humanos, como comprensivo, consciente de la importancia de la palabra escrita y llevado por sentimientos contradictorios, a veces la ira, otras la decepción. Por el otro lado, Corvalán es un general retirado pero humano y bonachón, que hace consideraciones acerca de la sexualidad en tiempos de guerra; es como un abuelo patriarcal pero no autoritario, su voz cordial invita a escucharlo sin despertar sentimiento de rechazo que su carrera militar podría despertar en quienes construyen la memoria en torno a la militancia setentista. Su presencia permite no solo divulgar la imagen del héroe desde un punto de vista de con quién pueden identificarse jóvenes y adultos, sino también introducir la pregunta crucial "Qué es la Patria?", seguida por una descripción de la composición transnacional del ejercito sanmartiniano y expresión de desdeño al referente territorial del concepto Patria.

Con la pregunta “Qué es la Patria?”, en el minuto 21', la película alude a una de las cuestiones más trascendentales en la era de la globalización: la desterritorialización, concepto que no se refiere sólo a los capitales que 'fugan' y 'fluyen', a los recursos naturales privatizados y a la distribución en diferentes lugares del globo de la cadena de producción de las empresas transnacionales. La desterritorialización es un proceso en lo simbólico que desarticula el referente clave de las culturas, el espacio común donde se materializan las prácticas de agenciamiento que marcan las fronteras entre 'nosotros' y los 'otros'. La desterritorialización destruye el principio de centralidad y el de oposición entre lo interno y lo externo; dispersa el centro o foco cultural, y simultáneamente hace permeables las fronteras que distinguen un adentro de un afuera (Herner, 2009). En la pregunta de Corvalán, la película plantea alegóricamente la necesidad de redefinir Argentina en la era de la globalización, cuando su sistema productivo es sacudido por los conflictos financieros y políticos; con su estructura social dislocada y atemorizada ante el futuro imprevisible; con su composición demográfica que cambió rápidamente con las olas migratorias; con el sistema político trastornado por la impotencia de las fuerzas políticas mas tradicionales ante las crisis de 2001 y el alza del bloque histórico K. 


\section{The end}

De acuerdo a las convenciones del cine hecho al estilo hegemónico de Hollywood, las respuesta al interrogante "Qué es la Patria?" es proporcionada por la misma película en las dos escenas finales. De este modo, recordando que "Pensar y desterritorializar quiere decir que el pensamiento sólo es posible en la creación, y para que se cree algo nuevo es fundamental romper el territorio existente, creando otro" (Herner, 2009, p. 169), el cierre de los conflictos e interrogantes abiertos a lo largo del film, produce la catarsis en sus espectadores y reterritorializa la identidad argentina. Cuando se escucha a San Martín informando el triunfo en Chacabuco y las vivas a la Patria de sus soldados en 1817 mientras se ven las víctimas y los heridos, se manifiesta que la Patria se consigue luchando y sacrificando. Cuando el periodista que hace el reportaje a Corvalán en 1880 acepta que el viejo reúna a su alrededor en la fotografía final a los chicos y las mujeres que cohabitan el conventillo, se comprende que la Patria es la inclusión de todos en la narrativa heroica. El periodista y su cámara simbolizan en modo reflexivo los artificios culturales que registran la Memoria. De este modo, presenciar Revolución: El cruce de los Andes, artificio cultural producido por instituciones y personas identificados con el discurso $\mathrm{K}$, se instituye como una practica de agenciamiento por la cual los espectadores recuperan un territorio simbólico y vuelven a percibirse como 'nosotros', un ser colectivo que, convocado por el discurso K y confortado por el culto K, se siente partícipe de la construcción de la Patria.

\section{Notas}

1. El anuncio de la producción del film por la presidenta Fernández de Kirchner no mencionó a Ibermedia, no habiendo logrado el autor del presente artículo averiguar las circunstancias por las cuales dicho fondo se apartó o fue apartado del proyecto. El sitio web del Programa Ibermedia anuncia estar en mantenimiento y no proporciona datos sobre las producciones de los años anteriores. Disponible en: http://www.programaibermedia. com/. Consultado 25/5/2012.

2. Ismail Xavier (1999). Allegory and History, in: A Companion to Film Theory, (eds.) Robert Stam and Toby Miller (pp. 333-362). Oxford and New York: Oxford University Press. La Rosales (Lipszyc, 1982) alegoriza en el juicio militar realizado en 1893 a oficiales de la Armada Nacional, la desconfianza ante la impunidad enraizada en la sociedad, que se vio confirmada en las leyes del Punto Final y la Obediencia Debida, cuando el gobierno de Menem indultó en 1990 a los altos mandos de la dictadura, enjuiciados en 1983 y condenados en 1985. Tzvi Tal (2010). "La Rosales: Historia, Intertextualidad y Alegoría en una película de la democratización en Argentina”. Història \& Cinema, (Ed.) José María Caparrós Lera (pp. 243 - 262). Barcelona: Publicacions i Edicions Universitat de Barcelona.

3. También Diarios de motocicleta es un producto adaptado a los circuitos de comercialización y exhibición globales, donde realiza un trabajo ideológico de despolitización de la memoria del personaje histórico, consagrando la memoria de Che Guevara como si fuera un apóstol cristiano. Tzvi Tal, "Geografía y conciencia social: tres versiones fílmicas del 
viaje de Ché Guevara”, VII Encontro Internacional da ANPHLAC, PUC-Campinas 10 a 13 october 2006. Ponencia.

\section{Bibliografía}

Althusser, L. (1971). Lenin y la filosofía. Buenos Aires: Carlos Pérez editor.

Álvarez, J. A. (2004). La desmonumentalización en la novela histórica hispanoamericana a fin del siglo veinte, Ph. D. dissertation, University of Texas. Disponible en: http://repositories.lib.utexas.edu/handle/2152/1469. Consultado el 22/1/2010.

Álvarez Valencia, J.; Rubio, L.; Andrés, C.; Latorre, L. y Pérez, N. (2009). Programa Ibermedia 1998-2008. Evaluación - 10 años de apoyo al Cine Iberoamericano. Madrid: Fundación para la Investigación del Audiovisual / Universidad Internacional Menéndez Pelayo.

Arnolfi, J. (2011). San Martín es un revolucionario a secas, un héroe latinoamericano, Miradas al Sur. Disponible en: http://sur.infonews.com/notas/san-martin-es-un-revolucionario-secas-un-heroe-latinoamericano. Consultado el 20/4/2012

Bietti, L. M. (2009). Entre la cognición política y la cognición social: el discurso de la memoria colectiva en Argentina, Discurso \& Sociedad, 1, 44-89.

Bugallo, Matías (2011). Leandro Ipiña: Para hacer esta película use de posavasos mis manuales de la escuela. Disponible en: http://www.rockandball.com.ar/leandro-ipina-laburamos-con-libertad-absoluta-desde-el-gobierno-nacional-solo-recibimos-elogios/. Consultado 28/4/2012.

Canal Encuentro. Disponible en: www.encuentro.gov.ar/content.aspx?id=2148; www.en cuentro.gov.ar/nota-3824-Revolucion-El-cruce-de-Los-Andes-Presentacion-especial-. html. Consultado el 20/4/2010.

Cinelli, J. P. (2011). La pregunta por la patria Página 12, 7/4/2011 Disponible en: www.pa gina12.com.ar/diario/suplementos/espectaculos/5-21305-2011-04-07.html. Consultado el 15/3/2012.

Comolli, J.-L. and Narboni, J. (1969, 1985). Cinema/Ideology/Criticism, in Movies and Methods, Vol. 2 Ed. Bill Nichols (pp. 22-30). Berkeley: University of California Press.

De Riz, L. (2010). La clase media argentina: conjeturas para interpretar el papel de las clases medias en los procesos políticos, en Clases medias y gobernabilidad en América Latina, Martín Hopenhayn et al., (pp. 69-102). Madrid: Editorial Pablo Iglesias.

Di Meglio, G. (2010). Revolución - el cruce de los Andes. Buenos Aires: Educar.

Falicov, T. (2007). Programa Ibermedia: Co-Production and the Cultural Politics of Constructing an Ibero-American Audiovisual Space, Spectator 2, 21-30.

Filmus, D. (2012). Un estado recuperado, Página 12, 25/4/2012. Disponible en: www.pagi na12.com.ar/diario/elpais/1-192603-2012-04-25.html. Consultado el 5/5/2012.

Godio, J. (2006). El tiempo de Kirchner - el devenir de una 'revolución desde arriba'. Buenos Aires: Letra Grifa.

Herner, M. T. (2009). Territorio, desterritorialización y reterritorialización: un abordaje teórico desde la perspectiva de Deleuze y Guattari, Huellas 13, 158 - 171.

Korstanje, M. E. (2011). El culto K en la era contemporánea: Crónica, génesis y apoteosis 
del proceso Kirchnerista, Contribuciones a las Ciencias Sociales. Disponible en: www.eumed.net/rev/cccss/13/. Consultado el 28/4/2012.

Lewkowicz, J. (2012). España, la peor de todas, Página 12, 2/5/2012. Disponible en: www. pagina12.com.ar/diario/economia/2-193070-2012-05-02.html. Consultado el 3/5/2012. Lynch,J.(2009). San Martín:Argentine Soldier, American Hero.London:Yale University Press. Magrini, A. L. y Quiroga, M. V. (2011). A diez años de diciembre de 2001: de la protesta social, luchas, desafíos y reinvenciones de lo político, Estudios 26, 59-79.

Mar-Molinero, C. (2006). The European Linguistic Legacy in a Global Era: Linguistic Imperialism, Spanish and the Instituto Cervantes, en: Language Ideologies, Policies and Practices: Language and the Future of Europe, eds. Clare Mar-Molinero and Patrick Stevenson (pp. 76-91). Basingstoke: Palgrave Macmillan.

Montero, A. S. (2009). Puesta en escena, destinación y contradestinación en el discurso kirchnerista (Argentina, 2003-2007) Discurso \& Sociedad 2, 316- 347.

Muñoz, M. A. y Retamozo, M. (2008). Hegemonía y discurso en la Argentina contemporánea: Efectos políticos de los usos de 'pueblo’ en la retórica de Néstor Kirchner. Perfiles latinoamericanos 31, 121-149.

Novaro, M. (2012). Populismo radical, crisis políticas y 'revolución legal' en América Latina, Democracias 1, 29-63.

Perfil 14/8/2009. Galería: Cristina Kirchner homenajea a San Martín. Disponible en: www. perfil.com/contenidos/2009/08/14/noticia_0008.html. Consultado el 3/3/2011.

Philp, M. (2009). Los guardianes de la memoria del Padre de la Patria - Usos de la memoria de San Martín en la historia argentina reciente, Diálogos 3, 553-571.

Portelli, H. (1974). El rol de los intelectuales en el seno del Bloque Histórico, en Portelli, H. (1974), Gramsci y el Bloque Histórico (pp. 93-118). Buenos Aires: Siglo Veintiuno.

Proyecto Libertadores. Disponible en: www.loslibertadores.net/downloads/libertadores_ v6.pdf ; www.loslibertadores.net/proyecto.php ; www.wandafilms.com/site/compania ; http://www.empresite.com/LUSA-FILMS.html. Consultado el 24/4/2012.

Raiter, A. (2009). Hablo y entiendan: creencias, presuposición e interdiscurso en los actos de Cristina Fernández de Kirchner. Oralia: Análisis del discurso oral, 12, 73-96.

Rocca Rivarola, M. D. (2001). Definiciones de pertenencia de identidades oficialistas en la Argentina de Nestor Kirchner y el Brasil de Luiz Inacio Lula da Silva, en Ciudadanía y legitimidad democrática en América Latina, comp.Isidoro Cheresky, (pp. 79-138). Buenos Aires: Prometeo.

Rockandball. Periodismo sin filtro. (15/04/2011). Entrevista con Leandro Ipiña. Disponible en:http://www.rockandball.com.ar/leandro-ipina-laburamos-con-libertad-absoluta-des de-el-gobierno-nacional-solo-recibimos-elogios/ Consultado 28/4/2012.

Sarlo, B. (2004). Nunca mas el discurso único, Página12, 28/3/2004. Disponible en: http:// www.pagina12.com.ar/diario/elpais/1-33360-2004-03-28.html . Consultado el 1/2/2012.

Tal, T. (2011). Imágenes prostituidas: inmigrantes latinoamericanas en Princesas y En la puta vida, El Otro en la España contemporánea - Prácticas, discursos y representaciones, (eds.) Silvina Schammah Gesser y Raanan Rein (pp. 337-360). Sevilla: Tres Culturas. (2010a). La Rosales: Historia, Intertextualidad y Alegoría en una película de la democratización en Argentina. Història \& Cinema, (Ed.) José María Caparrós Lera (pp. 243 - 262). Barcelona: Publicacions i Edicions Universitat de Barcelona. 
(2010b). Libertadores de celuloide: San Martín y Bolívar en películas de la globalización. HAL-SHS (Hyper Article en Ligne - Sciences de l'Homme et de la Société). Disponible en: http://halshs.archives-ouvertes.fr/halshs-00496211/fr/. Consultado el 28/4/2012. (2006). Geografía y conciencia social: tres versiones fílmicas del viaje de Ché Guevara, VII Encontro Internacional da ANPHLAC, PUC-Campinas, 10 a 13 octubre. Ponencia. (2004). San Martín, from Bronze to Celluloid: Argentina's Liberator as Film Character, Film \& History 34, 21-30.

Taquilla Nacional, El desempeño comercial de Revolución: El Cruce de los Andes en su primer fin de semana (2011). Disponible en: http://marianoliveros.wordpress.com/2011 /04/11/el-desempeno-comercial-de-revolucion-el-cruce-de-los-andes-en-su-primerfin-de-semana/. Consultado el 23/4/2012.

Villazana, L. (2009). Transnational Financial Structures in the Cinema of Latin America: Programa Ibermedia in Study, Saarbrücken: VDM Verlag.

Xavier, I. (1999). Allegory and History, en A Companion to Film Theory, (eds.) Robert Stam and Toby Miller (pp. 333-362). Oxford and New York: Oxford University Press.

Summary: The figure of the Liberator General Jose de San Martin was incorporated into the Pantheon of National Heroes of Argentina around 1870, long after the emancipation wars. Despite his memory was consecrated, institutionalized and any alternative image penalized, the changing image of San Martin in film testifies turns in the discourse that the social and political conflicts generated. This article argues that the image of the Liberator in "Revolution: The crossing of the Andes" (Ipiña, 2010) disseminate the discourse of the late President Nestor Kirchner and the current president Cristina Fernandez de Kirchner, also nicknamed "discourse K", taking part in the reconstruction of the Argentina identity convened by this discourse and the historic bloc conformed around its project.

Keywords: discourse - film - identity - San Martín - Kirchner.

Resumo: A figura do Libertador General José de San Martín foi incorporada ao Panteão dos Heróis Nacionais da República Argentina em 1870, muito depois da epopéia emancipadora. Sua memória foi consagrada, institucionalizada e toda imagem alternativa penalizada, apesar da cambiante imagem cinematográfica do Prócer testemunha os giros no discurso que os conflitos sociais e políticos geravam. Este artigo sustenta que reconstruindo a imagem do Libertador, o filme Revolución: El cruce de los Andes (Ipiña 2010) difunde o discurso do expresidente Nestor Kirchner e da presidente atual Cristina Fernández de Kirchner, também apodado "discurso K". O filme manifesta a reconstrução da identidade argentina convocada por o discurso K, e o discurso histórico construído ao redor do seu projeto.

Palavras chave: cinema - discurso - identidade - Kirchner - San Martín. 